\title{
Abuso de idosos e o papel dos profissionais de saúde
}

Inês Filipa Santos Almeida, ${ }^{1}$ César Lares dos Santos, ${ }^{2}$ Duarte Nuno Vieira ${ }^{3}$

\section{RESUMO}

Objetivos: Analisar a perspetiva dos profissionais de saúde sobre o abuso de idosos e avaliar as dificuldades experienciadas na abordagem deste tipo de casos, concretizando-se, complementarmente, uma revisão de conceitos fundamentais relacionados com esta temática.

Fontes de dados: Pesquisa nas bases de dados PubMed, MEDLINE, Embase, Repositórios Científicos de Acesso Aberto de Portugal e OpenAIRE. Foi ainda consultado o Código Deontológico da Ordem dos Médicos, o Código Deontológico dos Enfermeiros, o Código Penal e a informação disponibilizada nos sites da Organização Mundial da Saúde, Direção-Geral da Saúde e Associação Portuguesa de Apoio à Vítima.

Métodos de revisão: Pesquisa nas bases de dados através da combinação dos seguintes termos: abuso; maus-tratos; idosos; profissionais de saúde; pessoal de saúde; Portugal.

Resultados: Foram selecionados 32 artigos científicos originais, publicados entre 2010 e 2018, disponíveis na sua totalidade em português e/ou inglês, com conteúdos direcionados para os objetivos delineados.

Conclusões: A falta de deteção e de adequada orientação, por parte dos profissionais da saúde, de situações abusivas contra as pessoas idosas pode estar associada a défices na formação sobre este tema, sendo crucial melhorar os conteúdos curriculares neste domínio. A formação deve focar as situações que podem ser consideradas abusivas, os sinais e sintomas associados, o contexto em que os abusos podem ocorrer, a legislação existente e as autoridades a que se pode recorrer. Associadamente deve promover-se a consciencialização do público em geral, realçando a importância da deteção precoce e as instituições disponíveis para fornecer apoio aos idosos vulneráveis.

Palavras-chave: Maus-tratos; Idoso; Pessoal de saúde; Portugal.

\section{INTRODUÇÃO}

A Organização Mundial da Saúde (OMS) define o abuso de idosos como "um ato simples ou repetido, ou ausência de ação apropriada, que ocorre no contexto de qualquer relacionamento em que haja uma expetativa de confiança, que causa dano ou angústia a uma pessoa idosa"..$^{1-18}$ Esta definição de abuso compreende a noção de confiança, isto é, os atos são perpetrados por alguém em quem o idoso deposita confiança, o que, por si só, é suscetível de constituir fator favorecedor da ocultação prolongada da situação abusiva por parte da vítima, com o intuito de proteger o abusador.

A primeira abordagem desta temática na literatura médica terá ocorrido em 1975, no contexto de carta di-

1. Mestranda. Faculdade de Medicina, Universidade de Coimbra.

2. Assistente Convidado. Faculdade de Medicina, Universidade de Coimbra.

3. Professor Catedrático. Faculdade de Medicina, Universidade de Coimbra. rigida por Burston ao editor do British Medical Journal, intitulada Granny battering. ${ }^{19}$ Neste mesmo ano, Baker publicaria um artigo com o mesmo título na revista $\mathrm{Mo}$ dern Geriatrics. ${ }^{20}$ Todavia, apesar do tempo decorrido desde então, o abuso de idosos só mais recentemente viria a suscitar um interesse acrescido, nomeadamente pela circunstância de a população idosa vir aumentando exponencialmente a nível global, face ao aumento da esperança média de vida. ${ }^{-6-6,8-9,15,21-23}$ A OMS estima uma duplicação da população mundial acima dos 60 anos de idade para 2050, em relação a 2015, passando dos 900 milhões (12,3\% da população total) para os 2 biliões ( $21,5 \%$ da população). A determinação da prevalência atual do abuso de idosos tem-se revelado uma tarefa complexa, designadamente em virtude das variadas metodologias utilizadas ${ }^{4,6,9,24} \mathrm{e}$ das diferentes populações estudadas. ${ }^{9,35}$ Esta dificuldade encontra-se espelhada, por exemplo, numa revisão sistemática efe- 
tuada em 2015 por Dong, que referia taxas de prevalência variando de 2,2 a $61,1 \% .^{25}$

Diversos estudos indiciam tratar-se, efetivamente, de um problema comum. Ainda assim, muitos dos profissionais de saúde que trabalham com pessoas idosas afirmam nunca terem detetado um caso de abuso de idosos, ${ }^{15,17}$ situação que suporta a tese defendida por alguns autores de que os casos reportados constituem somente a "ponta do icebergue» ${ }^{6,15,24}$ e que mais de $80 \%$ dos casos de abuso de idosos nunca são denunciados ou reportados a nenhuma entidade, ${ }^{6,18,26}$ apesar de se tratar de uma situação transversal a todas as classes socioeconómicas a nível mundial. Na mesma linha, a literatura revela que somente um em cada $24,{ }^{25-27} \mathrm{um}$ em cada $14^{28}$ ou um em cada cinco casos de abuso de ido$\operatorname{sos}^{29}$ são efetivamente denunciados.

A relevância médica do abuso é amplamente reconhecida atendendo às consequências nefastas que acarreta para a saúde da vítima, quer em termos de aumento da mortalidade ${ }^{2,9,16,26-27,30,33,36}$ quer de morbilidade, com subsequente diminuição da qualidade de vida ${ }^{1,5,9,11,21,36}$ em comparação com idosos que não sofreram abuso. Adicionalmente, tem sido associado a um aumento do risco de recorrência ao serviço de urgência, ${ }^{30-31,33}$ hospitalização ${ }^{26-27,30-31,33} \mathrm{e}$ institucionalização em lar, ${ }^{26,30-31,33}$ bem como a depressão $0^{8,26-27,30,32} \mathrm{e}$ ansiedade. ${ }^{16,27,32}$ Alguns autores referem ainda o desenvolvimento de isolamento social por parte da vítima, ${ }^{8,32}$ assim como sentimentos de culpa ${ }^{8}$ e stress pós-traumático. ${ }^{32}$

Para evitar estas possíveis consequências, é indispensável o contributo dos profissionais de saúde, os quais se encontram numa posição privilegia$\mathrm{da}^{4,6,9,13,18,24,26,28-30,34,37}$ para o diagnóstico e orientação deste tipo de casos, já que podem ser a única pessoa, para além do abusador, a contactar com a vítima. O estudo de O'Brien e colaboradores realça o papel valioso dos médicos de medicina geral e familiar, salientando que a possibilidade destes realizarem visitas ao domicílio pode permitir a identificação de casos que, de outra forma, poderão não ser detetados. ${ }^{34}$ Também Leddy e colaboradores destacam a importância dos médicos ginecologistas-obstetras, dado que as mulheres correm maior risco de sofrer abuso, ${ }^{8,21,27,38}$ sendo que estes tratam mulheres ao longo de toda a vida (mulheres com mais de 65 anos ainda frequentam a 1,3 consultas por ano). ${ }^{27}$ Apesar disso, o estudo de Schmeidel e colaboradores afirma que mais de metade dos médicos nunca procuraram avaliar potenciais abusos no contexto das suas consultas com pacientes idosos. ${ }^{29}$

Neste contexto, procedeu-se a uma revisão crítica da literatura no sentido de melhor compreender a perspetiva dos profissionais de saúde sobre esta temática e de avaliar as dificuldades sentidas na abordagem deste tipo de situações. Por se considerar pertinente para a obtenção de uma perspetiva mais holística da temática em apreço, efetuou-se, complementarmente, uma revisão de aspetos conexos tidos como relevantes, nomeadamente, tipologia de abuso, sinais/indicadores e alguns aspetos epidemiológicos.

\section{MÉTODOS}

Procedeu-se à revisão da literatura através da pesquisa na PubMed, MEDLINE, Embase, Repositórios Científicos de Acesso Aberto de Portugal (RCAAP) e OpenAIRE, utilizando uma combinação dos seguintes termos: abuso; maus-tratos; idosos; profissionais de saúde, pessoal de saúde; Portugal. Foram selecionados somente artigos originais, publicados entre 2010 e 2018 e disponíveis em português e inglês e, destes, somente os que se encontravam disponíveis para leitura na sua totalidade e em que o conteúdo se encontrava alinhado com os objetivos propostos. Foram selecionados no total 32 artigos científicos.

Adicionalmente foi consultado o Código Deontológico da Ordem dos Médicos, o Código Deontológico dos Enfermeiros e o Código Penal, assim como a informação constante nos sites da Organização Mundial da Saúde (OMS), da Direção-Geral da Saúde (DGS) e da Associação Portuguesa de Apoio à Vítima (APAV).

\section{RESULTADOS}

\section{Definição e tipologias do abuso de idosos}

O abuso pode expressar-se por várias modalidades: física (inflição de dor ou lesão, coação física ou domínio induzido pela força ou por drogas); psicológica (inflição de angústia mental sob a forma de ameaças, insultos, humilhação, infantilização); financeira (exploração ilegal ou imprópria dos fundos ou recursos do idoso, apropriação indevida dos bens do idoso, alteração forçada do seu testamento, negação ao acesso dos seus próprios fundos e bens pessoais); sexual (contac- 
to sexual não consensual, de qualquer tipo, com o idoso); ou negligência (recusa ou falha em desempenhar a obrigação de cuidar do idoso), intencional ou não intencional. ${ }^{1,3-8,10-12,21,26,28-29,30-33,37-38}$ Pode ocorrer isoladamente ou em associação, ${ }^{6,30}$ designando-se a exposição de uma vítima a dois ou mais tipos de abuso por polivitimização. $^{5}$

\section{Prevalência}

Como anteriormente assinalado, a determinação da prevalência atual de idosos abusados tem-se mostrado uma tarefa complicada.

A prevalência mais baixa de abuso de idosos, de 1,4 a 5,4\%, é apresentada por Wagennar e colaboradores, citando o estudo The National elder abUSE INCIDENCE STUDY: FINAL REPORT, de 2009..$^{28}$ Todavia, outros autores acreditam que o abuso de idosos poderá, na realidade, atingir valores tão elevados quanto $10 \%,{ }^{10,26,35-36} 20 \%^{24}$ ou 30\%. ${ }^{9,23}$ Alguns estudos, citando uma revisão sistemática de Sooryanarayana e colaboradores, de 2013, referem que a prevalência pode atingir os $44,6 \%$, ou seja, praticamente metade da população idosa. ${ }^{4,32}$ No entanto, Dong (citado por Eslami e colaboradores), numa revisão sistemática de 2015, afirma que o abuso de idosos pode atingir mais de metade da população idosa, com uma prevalência de 2,1 a $61,1 \%,{ }^{3}$ sendo este o valor mais alto sugerido até à data.

Relativamente à realidade nacional, o estudo ENVELHECIMENTO E VIOLÊNCIA (2014) estima que $12,3 \%$ da população portuguesa acima de 60 anos foi vítima de, pelo menos, um ato de abuso nos 12 meses anteriores à sua realização, tendo este sido perpetrado por parte de um familiar, amigo, vizinho ou profissional de saúde remunerado. ${ }^{10}$

As dificuldades inerentes ao cálculo da incidência e prevalência atual estendem-se também à determinação do tipo de abuso mais frequentemente perpetrado. Em estudos realizados em indivíduos de sete países europeus (Alemanha, Espanha, Grécia, Itália, Lituânia, Portugal e Suécia), com idade entre 60 e 84 anos, o abuso psicológico foi mencionado como o tipo mais frequente, ${ }^{23}$ sendo $o$ abuso financeiro o segundo mais frequente, ${ }^{22}$ seguido pelo abuso físico e, por último, como o tipo menos habitual, o abuso sexual. ${ }^{3}$ No estudo de O’Brien e colaboradores, os clínicos gerais da Irlanda estimaram tanto o abuso psicológico como a negli - gência como as formas mais frequentes de abuso e os abusos físico e sexual como as menos frequentes. ${ }^{34}$ Por outro lado, segundo Sandmoe e Kirkevold, os profissionais de saúde da Noruega consideram que o tipo de abuso mais frequente é o abuso físico e, muitas vezes, rotulam os outros tipos de abuso, ou mesmo casos menos graves de abuso físico, como algo que não é abuso, como «casos difíceis». ${ }^{16}$ De forma semelhante aos estudos europeus mencionados, no projeto ENVELHECIMENTO E VIOLÊNCIA, já assinalado, e referente à população idosa portuguesa, a negligência e o abuso sexual foram identificados como os tipos menos frequentes de abuso e o abuso financeiro e psicológico como sendo os mais frequentes..$^{10,21,38}$ Gil e colaboradores também identificam a negligência e $\mathrm{o}$ abuso sexual como as formas menos frequentes de abuso, destacando o abuso físico e o psicológico como os mais frequentes. ${ }^{5}$ Ainda sobre a realidade nacional, mas relativamente a vítimas portadoras de deficiência física ou mental moderada ou grave antes do episódio de abuso, o estudo de Frazão e colaboradores reconhece que o tipo mais habitual de abuso de idosos é o físico. ${ }^{9}$ Particularizando para a região centro de Portugal, aponta-se o abuso psicológico e a negligência como as formas mais detetadas de abuso. ${ }^{8}$ Já outros autores estudaram a perceção que os profissionais de saúde de cuidados de saúde primários da zona de Coimbra tinham sobre a prevalência de abuso de idosos em Portugal, sendo que a negligência e o abuso psicológico foram escolhidos por $32,3 \%$ e $22,1 \%$ dos profissionais, respetivamente, como os tipos de abuso mais prevalentes, ${ }^{6}$ o que corrobora os achados na literatura. ${ }^{8}$

Ainda sobre o apurado relativamente à realidade portuguesa, o projeto ENVELHECIMENTO E VIOLÊNCIA refere que a maioria dos idosos vítimas de abuso experienciou apenas um tipo de abuso e que só cerca de 2 a $3 \%$ dos idosos vivenciaram situações de polivitimização. ${ }^{10,38}$

Os atos abusivos podem ocorrer ocasionalmente ou de forma continuada, ${ }^{21}$ quer no domicílio quer em contexto de institucionalização. ${ }^{12,21}$ Sobre a realidade nacional reportamo-nos a estatísticas disponibilizadas pela APAV sobre as pessoas idosas vítimas de crime e de violência apoiadas por aquela associação entre os anos de 2013 a 2016, período durante o qual se identificou que mais de metade das situações de abuso ocorreram no domicílio. ${ }^{39}$ De notar que no estudo efetuado 
por Ferreira e colaboradores, os profissionais de saúde de cuidados primários de unidades da região de Coimbra que integraram a amostra também indicaram acreditar que o abuso de idosos acontece em maior frequência neste contexto. ${ }^{6}$

\section{Perfis e fatores de risco do agressor e vítima}

Embora o abuso possa ser perpetrado por familiares, cuidadores ou outras pessoas de confiança ${ }^{12}$ tem-se verificado que, na maioria dos casos, os abusadores são familiares da vítima..$^{5,933}$ Destes, a maioria pertence à família nuclear, nomeadamente cônjuges/parceiros (atuais ou ex) ou descendentes. ${ }^{5,9,38}$ Há ainda autores que referem outros familiares como uma parte relativamente significativa dos abusadores, o que inclui irmãos(ãs), sobrinhos(as) e cunhados(as). ${ }^{10,33,38}$ Além destas categorias de abusadores, o projeto ENVELHECIMENTO E VIOLÊNCIA identificou ainda amigos/vizinhos como possíveis agressores em $11,6 \%$ das situações. ${ }^{10}$

A literatura destaca que existem diferenças no tipo de abusador consoante o género da vítima, já que nas vítimas do sexo feminino o abuso foi perpetrado principalmente pelo cônjuge/parceiro, enquanto nas vítimas do sexo masculino os principais abusadores identificados foram os descendentes do sexo masculino. ${ }^{5}$ Muitos autores reforçam a ideia de que o abuso é cometido principalmente por indivíduos do sexo masculino, ${ }^{9-10,39}$ o que, estando as mulheres idosas em maior risco de sofrer abuso, ${ }^{8,21,27,38}$ pode apoiar a ideia de que a maior parte dos comportamentos abusivos são perpetrados pelo cônjuge/parceiro destas possíveis vítimas. Em sentido contrário, o estudo de Vognar e Gibbs afirma que mais de metade dos abusadores são mulheres. ${ }^{33}$

Segundo a OMS, o grau de ocorrência de atos abusivos contra pessoas idosas pode ser ponderado através da análise de fatores individuais, referentes à potencial vítima e abusador, e fatores associados ao relacionamento entre eles, ao enquadramento comunitário e ao contexto social. ${ }^{21} \mathrm{~A}$ maioria dos autores acredita que pessoas idosas do sexo feminino, ${ }^{8,21,38} \mathrm{com}$ maior idade (superior a 74 anos), ${ }^{8,12,21,33,38}$ baixo nível de escolaridade, ${ }^{5,8,38}$ dependência física e/ou intelectual, , $, 69-10,12,21,27,31,33,38 \mathrm{de}$ mência, ${ }^{6,9,21,33,36}$ depressão $0^{21,38}$ ou comportamento agressivo e desafiante ${ }^{1,21}$ se encontram em risco acrescido de sofrerem abuso. Relativamente ao abusador, parece que ser do sexo masculino potencia atos abusivos de caráter físico, enquanto o sexo feminino potencia atos de negligência. ${ }^{21}$ Além disso, depressão, ${ }^{1,12,21}$ perturbação mental, ${ }^{1,6,12}$ consumo de álcool, ${ }^{1,5-6,21}$ abuso de substâncias,,$^{1,5,21}$ hostilidade e agressividade, desemprego, ${ }^{9,38}$ problemas financeiros ${ }^{6,21,38}$ e stress/burnout enquanto

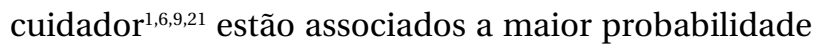
de cometer abuso. Ainda sobre o abusador e a sua relação com a potencial vítima são apontados como fatores de risco a dependência financeira do agressor face à vítima, ${ }^{1,5,12,21,38}$ coabitação, ${ }^{1,5,5,2,1,38}$ história de relacionamento difícil, ${ }^{5,21,38} \mathrm{o}$ abusador ser descendente ou cônjuge/parceiro da vítima e a possível transmissão intergeracional de condutas violentas. ${ }^{21}$ No que diz respeito ao enquadramento comunitário e contexto social acredita-se que o isolamento social da possível víti$\mathrm{ma}^{1,9,12,21,27,31,33,38}$ e a carência de suporte social estão associados a maior probabilidade de sofrer abuso. ${ }^{21}$ Além disso, é importante considerar o idadismo, isto é, a discriminação com base na idade e a atual banalização da violência. ${ }^{1,21}$

Embora não haja consenso quanto ao grau em que o género influencia a probabilidade de sofrer abuso, as mulheres são indicadas como mais suscetíveis de sofrer abuso em geral, ${ }^{8,21,27,38}$ o que pode ser explicado pela sua esperança de vida superior, já que, vivendo mais, são também mais afetadas pela incapacidade física e/ou intelectual, tornando-se mais suscetíveis a atos abusivos..$^{38}$ Ainda assim, um estudo nacional destaca que ser do sexo masculino aumenta o risco de sofrer negligência. ${ }^{8}$

Apesar de ter uma idade mais avançada constituir um fator de risco para o abuso em geral, ${ }^{8,12,21,33,38}$ há autores que mencionam que uma menor idade pode também ser considerada como fator de risco, uma vez que poderá estar relacionada com uma maior probabilidade de autorreportar atos abusivos. ${ }^{3}$ Nestes casos, a menor idade associa-se mais a abuso físico ou psicológico $^{3,5}$ ou ainda a abuso financeiro. ${ }^{8}$ Relativamente ao nível de escolaridade, um nível mais baixo tem sido apontado como um fator de risco para o abuso em geral; $;, 8,38$ contudo, alguns autores apontam o ensino superior como um fator de risco para abuso psicológico ${ }^{3,23} \mathrm{ou}$ abuso financeiro. ${ }^{23} \mathrm{Um}$ estudo refere ainda que o consumo de álcool por parte da vítima aumenta o risco de esta sofrer abuso físico ou psicológico. ${ }^{3}$ 
Quanto a fatores de proteção, o estudo de Eslami e colaboradores destaca que viver em parceria protege contra abuso físico ou financeiro, reforçando a importância do apoio social; todavia, é necessário ter em conta que ter o cônjuge/parceiro como fonte de financiamento duplica o risco de sofrer exploração financeira. ${ }^{3}$ No projeto ENVELHECIMENTO E VIOLÊNCIA, a educação foi identificada como um fator protetor contra o abuso, sendo que quanto maior for o nível de instrução de um indivíduo menor a probabilidade de sofrer atos abusivos. ${ }^{10}$

Relativamente à polivitimização, esta pode afetar tanto homens como mulheres, sendo transversal a todos os grupos etários. ${ }^{5}$

\section{Indicadores de abuso}

Para além dos fatores de risco que predispõem os indivíduos idosos a situações abusivas, é também importante conhecer os diversos sinais e sintomas possivelmente associados aos vários tipos de abuso de idosos.

Deve-se suspeitar de abuso físico ao idoso quando existem marcas ou lesões cutâneas inexplicadas, como feridas ou hematomas, ${ }^{12,21,33,37}$ especialmente se tiverem localização simétrica; lesões músculo-esqueléticas, como fraturas, luxações ou entorses; sinais de restrição da mobilidade, como marcas de cordas ou ligaduras nos pulsos; ${ }^{12,21}$ ou ainda quando o familiar ou o cuidador recusam que o idoso fique a sós com o profissional de saúde. ${ }^{21}$ Relativamente às lesões cutâneas, deve darse especial importância a lesões no pescoço ou na zona ulnar do antebraço, que são características de abuso físico. ${ }^{30}$ No caso de abuso físico são mais frequentes lesões na cabeça e no pescoço, uma vez que estas correspondem às áreas mais acessíveis. ${ }^{9} \mathrm{E}$, apesar das quedas serem comuns nas pessoas idosas, nem todos os hematomas são o resultado destas, como é o caso de lesões no peito, pálpebras, pescoço, escroto, abdómen, costas ou ombros. ${ }^{7}$ Assim, é importante perguntar tanto ao idoso como ao familiar ou ao cuidador as circunstâncias em que as lesões foram produzidas e apreciar a eventual coincidência/consistência das respostas obtidas. ${ }^{7}$ Hoover e Polson associam-se a estas duas opiniões e reforçam que é pouco provável que lesões no pescoço, abdómen, região posterior da perna e região ulnar do antebraço resultem de quedas acidentais, constituindo-se como possíveis sinais de abuso. ${ }^{12}$
No caso do abuso psicológico, tanto podem existir maus-tratos verbais como intimidação através de gritos e ameaças, humilhação, infantilização ou culpabilização, bem como, e ainda, maus-tratos não-verbais, nomeadamente ignorância ou ostracização e isolamento da pessoa idosa. ${ }^{21}$ Pode ainda existir um comportamento depreciativo e/ou controlador por parte do familiar ou cuidador. ${ }^{21}$

Quanto ao abuso financeiro deve-se desconfiar dele quando há apropriação indevida dos bens do idoso, alterações suspeitas do seu testamento, aquisição de serviços desnecessários ou despropositados ou existência de dívidas quando se sabe que a vítima dispõe de dinheiro suficiente para as pagar. ${ }^{21}$ Os profissionais de saúde raramente são capazes de identificar abuso financeiro; contudo, este não deixa de ser importante uma vez que, apesar de poder não ter consequências imediatas, pode culminar em negligência. ${ }^{30} \mathrm{E}$ as pessoas idosas acumulam recursos ao longo da vida, o que as torna particularmente vulneráveis a este tipo de abuso. ${ }^{3}$

Relativamente ao abuso sexual deve ser equacionado quando a vítima apresenta hematomas na região genital, hemorragias a nível anal ou vaginal inexplicadas ou infeções de transmissão sexual. ${ }^{21}$

No que diz respeito à negligência, esta pode ser ativa, quando o agressor atua com intencionalidade, ou passiva, quando resulta da ignorância ou negação de cuidados ao idoso. ${ }^{21}$ Deve pensar-se em negligência quando o idoso apresenta perda de peso, desnutrição e/ou desidratação; ${ }^{7,21,30,33,37}$ falta de higiene pessoal; ;1,30 úlceras de decúbito; ${ }^{7,21}$ falta de óculos, próteses dentárias ou auditivas; ${ }^{21}$ ou utilização de roupas inadequadas para a estação do ano. ${ }^{21,30}$

De modo idêntico ao que acontece nos outros tipos de violência, a deteção de fatores de risco e de sinais e sintomas associados a abuso, quando identificados isoladamente, não permite estabelecer, de forma imediata e clara, um diagnóstico de abuso de idosos. ${ }^{21} \mathrm{Um}$ dos aspetos que complexifica o diagnóstico é a diferenciação que os clínicos têm de estabelecer entre processos fisiopatológicos ou fisiológicos do envelhecimento normal e lesões físicas decorrentes do contexto de abuso. ${ }^{6,9,12}$ As condições subjacentes que mimetizam lesões intencionais ou predispõem o paciente a lesões devem ser observadas e possíveis reações adversas medicamentosas devem ser tidas em consideração. ${ }^{12}$ É de ex- 
trema importância observar a existência, ou não, de traumas/lesões antigas, doença óssea metabólica ou uso de anticoagulantes. ${ }^{12}$ É importante realçar que não existem exames laboratoriais capazes de detetar atos abusivos. ${ }^{12} \mathrm{O}$ estudo da coagulação e a contagem de plaquetas podem excluir uma condição clínica justificativa de hematomas de intensidade ou quantidade excessiva ou anormal; todavia, o fundamental para diferenciar lesões intencionais das não intencionais assenta no confronto entre a explicação facultada ser ou não minimamente consistente com os achados ao exame físico. ${ }^{12}$

\section{O papel dos profissionais de saúde}

Os profissionais de saúde têm um contacto significativo com a população geriátrica, estando numa posição privilegiada tanto para controlar e intervir nos fatores de risco, como para identificar precocemente sinais e/ou sintomas de abuso. ${ }^{4,6,9,13,18,24,26,28-29,30,34,37}$ Ainda assim, é uma temática que, além de preocupação, suscita também dúvidas e insegurança entre os profissionais de saúde, resultando na falta de denúncia destes casos. ${ }^{9}$

Uma das causas apontadas para a falta de denúncia por parte destes profissionais é a ocultação por parte da vítima, ${ }^{24,34}$ o que acontece maioritariamente para proteção do abusador ${ }^{5,10,21,33,38}$ e da família, ${ }^{5,738}$ já que, como previamente salientado, o abuso ocorre frequentemente no seio familiar. A vítima pode apresentar-se relutante em falar sobre o assunto por medo em geral, ${ }^{10,21,37}$ medo de retaliação ou agravamento da agressividade, ${ }^{5,9-10,12,28,33,37}$ medo do abandono $0^{5,28,37}$ ou por sentir vergonha da situação em que se encontra. ${ }^{7,-10,12,21,33}$ Além disso, muitos idosos dependem financeiramente do agressor, ,5,7,10,12,21,30 o que os pode levar a encobrir o abuso para proteger a sua subsistência. Por outro lado, os idosos podem sentir que merecem o abuso, ${ }^{7,9,21,37} \mathrm{e}$ não desejam criar problemas para os seus familiares, ${ }^{9,21,37}$ o que os pode levar a considerar o acontecimento como irrelevante. ${ }^{5,10,21}$ Muitos autores destacam ainda que as vítimas podem ser incapazes de divulgar o abuso por incapacidade física e/ou cognitiva, ${ }^{7,9,21}$ ter medo que ninguém acredite,,$^{5,9-10,38}$ não saber a quem recorrer $^{5,9-10}$ ou não confiar no sistema; ${ }^{21,33}$ no que diz respeito à relação com os profissionais de saúde, podem acreditar que estes não se interessam, já que têm pouca disponibilidade de tempo e nunca questionam os idosos sobre esta temática. ${ }^{21}$
Outra das causas fundamentais apontada pelos profissionais de saúde para o seu medo de denunciar casos de abuso de idosos é o facto de possuírem um conhecimento limitado sobre o tema. .,2,4, $, 12,27-29,33^{\text {Esta cir- }}$ cunstância correlaciona-se com a formação inadequada relativamente a este assunto e, consequentemente, à falta de conhecimento necessário para detetar casos de abuso ou abordar potenciais situações de risco. ${ }^{1,2,4,7,12,27-29,33}$ Ainda como causas para esta falta de denúncia é referido o receio de colocarem em risco a confiança da relação médico-doente,,${ }^{9,21,27-29}$ o receio de estarem enganados, ${ }^{6,28-29}$ a escassez de tempo ${ }^{9,26-27,29,31,34}$ e a incerteza sobre a obrigação de denunciarem os casos às autoridades judiciais. . $, 9,24,27^{2}$

Relativamente à relação médico-doente é importante destacar que cerca de metade dos profissionais de saúde defende que denunciar um caso de abuso de idosos não afeta esta relação. ${ }^{34}$ Mais raramente é referida uma sensação de impotência e incapacidade de fazer a diferença. ${ }^{21,31}$ Os profissionais de saúde podem ter medo de ser ameaçados pelo abusador e/ou pela família da vítima. ${ }^{34}$

Adicionalmente a todas as razões enumeradas, há ainda a considerar que os médicos hesitam em denunciar estes casos porque procuram ter a certeza absoluta da ocorrência de abuso e querem possuir informação suficiente antes de comunicar às autoridades. ${ }^{29}$ Além disso, os clínicos referem que é mais fácil desenvolver explicações alternativas para os possíveis hematomas e/ou fraturas do que equacionar a possibilidade de os cuidadores ou os familiares terem causado as lesões em questão. ${ }^{28}$ Os técnicos de emergência pré-hospitalar, em específico, sentem que têm a responsabilidade de denunciar situações suspeitas de abuso e sentem-se culpados se não o fizerem. ${ }^{35}$ Além das restrições de tempo a que estão sujeitos, a falta de protocolos e os problemas de comunicação aquando da tentativa de denúncia são fatores que favorecem a falta de denúncia. ${ }^{35}$ É uma grande responsabilidade moral, considerando que se poderá destruir a vida de alguém com base apenas na intuição. ${ }^{35} \mathrm{O}$ estudo de Leddy e colaboradores foca-se nos médicos ginecologistas-obstetras e afirma que os jovens médicos do sexo masculino pesquisam menos manifestações de abuso, o que poderá estar relacionado com a tenra idade. ${ }^{27}$ Pelo contrário, as médicas têm mais tendência a pesquisar potenciais situações abusivas e em eventualmente atuar, se necessário. ${ }^{27}$ 
Já os enfermeiros sentem que não faz parte do seu papel explorar possíveis situações abusivas e sentem-se mesmo desconfortáveis ao inquirir sobre abuso, pois foram orientados para concretizarem as suas funções rapidamente, como avaliar os sinais vitais, por exemplo. ${ }^{29}$ Assim sendo, se suspeitarem de abuso limitam-se na maioria das vezes a informar o clínico ou o assistente social para que estes aprofundem o assunto, contexto que leva a que nunca recebam feedback sobre o caso, ${ }^{37}$ reprimindo, consequentemente, a sua vontade de denunciar casos futuros. O estudo de Sandmoe e Kirkevold realça que somente dois em cada 52 enfermeiros abordam a situação diretamente com a vítima se suspeitarem de abuso, enquanto metade opta por falar com familiares e/ou com o abusador. ${ }^{16}$ De modo análogo, Leddy e colaboradores verificaram que metade dos ginecologistas-obstetras escolhe falar diretamente com os cuidadores, uma vez que somente metade dos profissionais sabe que muitas vezes o abuso é causado por esses mesmos. ${ }^{27}$ Esta conduta é oposta ao preconizado por Hoover e Polson, que destacam ser essencial falar com o idoso sozinho, sempre que possível, e encorajá-lo a fornecer detalhes sobre a sua situação. ${ }^{12}$

Por outro lado, os assistentes sociais, apesar de possuírem mais experiência para lidar com este assunto, confiam nos clínicos e enfermeiros para identificarem comportamentos abusivos. ${ }^{29}$

Nem os estudantes de medicina equacionam o abuso de idosos como diagnóstico diferencial até encontrarem provas quase incontestáveis, o que favorece a hipótese de existir uma falha na educação sobre este tópico. ${ }^{2}$ Além disso, muitos dos estudantes especulam que se estivesse a ocorrer abuso outros profissionais já o teriam identificado. ${ }^{2}$ No estudo de Fisher e colaboradores a situação abusiva apenas se tornou evidente quando foi encontrada a "marca da mão» na vítima; porém, se um diagnóstico alternativo e uma explicação clara para a situação tivessem sido encontradas no início da entrevista clínica é possível que não tivesse ocorrido exposição suficiente do paciente e, naturalmente, não tivesse sido encontrada a «impressão manual» do abusador. ${ }^{2}$ É também importante referir que os estudantes têm receio de rotular algo como abuso devido ao seu impacto negativo, pois consideram que é um termo muito julgador, intimidante e acusador. ${ }^{2} \mathrm{O}$ mesmo acontece com os outros profissionais de saúde que contactam com a população geriátrica. ${ }^{16,18}$ Muitas vezes o abuso é reportado como «dificuldades familiares» ou casos de bullying. ${ }^{16}$

Um dos pilares que fornece aptidão e confiança aos profissionais de saúde para detetar e reconhecer sinais e sintomas de abuso de idosos é a formação que recebem sobre o tema. ${ }^{18,28}$ Os médicos que referiram ter tido formação sobre este tema ou que participaram em atividades de educação médica continuada nos últimos cinco anos mais raramente afirmavam não reconhecer o abuso no momento da visita como uma barreira para não denunciar os casos; enquanto os médicos que não tinham frequentado atividades de educação médica continuada sobre este tópico estavam mais inclinados a afirmar não reconhecer o abuso como uma barreira. ${ }^{28}$

Explorando o currículo dos profissionais de saúde, a maioria refere que nunca teve qualquer referência a abuso de idosos durante a sua formação ${ }^{6,12,27-28,33,36} \mathrm{e}$, dos poucos que referem ter tido algum contacto com esta temática, a maioria acredita que deveria ter existido uma abordagem mais abrangente. ${ }^{6} \mathrm{O}$ estudo de Hempton e colaboradores assinala que $40,8 \%$ dos profissionais de saúde afirmam ter recebido alguns ensinamentos teóricos sobre o tema; contudo, $47,5 \%$ não teve qualquer ensinamento nem experiência prévia sobre a abordagem desta problemática. ${ }^{17}$ Já os enfermeiros tendem a conhecer melhor a burocracia relacionada com o abuso de idosos do que os clínicos, o que se atribui a possíveis diferenças na formação superior. ${ }^{24}$ Também existem diferenças entre os diversos tipos de clínicos, uma vez que os internistas são mais propensos a afirmar falta de formação quando comparados com os técnicos de emergência pré-hospitalar; ${ }^{28}$ o que parece contrariar outros estudos que referem que, durante o curso de certificação básica, os técnicos de emergência pré-hospitalar recebem apenas 30 minutos (ou menos) de treino sobre como abordar o abuso de idosos. ${ }^{35}$

Apesar de a maioria dos profissionais de saúde acreditar que a sua formação sobre abuso de idosos não é adequada ${ }^{28,33}$ e que o ensino sobre esta temática deveria ser mais aprofundado, ${ }^{18,29,33,37} \mathrm{o}$ problema parece não estar a ser abordado devidamente, já que $57,1 \%$ dos profissionais que integraram a amostra, com idade inferior a 30 anos, indicam não ter tido qualquer formação dirigida especificamente para o abuso de idosos. ${ }^{6}$ De notar que esta percentagem atinge o significativo va- 
lor de 95\% para profissionais com idade superior a 60 anos. ${ }^{6}$ Parece haver falta de educação sobre este tópico no curso de medicina e, para colmatar esta falha, deve ser preferido um ensino mais interativo que permita a discussão aberta dos casos, ao invés do ensino tradicional baseado na exposição teórica. ${ }^{2}$

Os estudos realizados neste âmbito sugerem que se deve fomentar a educação tanto dos atuais como dos futuros profissionais de saúde e que é necessária uma formação mais específica e focada nesta temática para proporcionar aos profissionais o conhecimento e a confiança para identificar e orientar eventuais situações abusivas. ${ }^{10-11,18,24,27-29,34,36}$

Segundo a OMS, durante a formação dos clínicos deve ser feita uma introdução ao tema, incluindo os sinais e sintomas associados ao abuso de idosos, destacando as organizações locais que possam dar assistência às vítimas e a avaliação de casos de abuso e sua gestão, salientando a importância de trabalhar com outros profissionais numa equipa multidisciplinar. ${ }^{1,40}$ Alguns autores defendem que é necessário clarificar a metodologia a utilizar na gestão destes casos e apoiam que os profissionais de saúde poderiam beneficiar de uma checklist a aplicar em situações de risco ou de suspeita. ${ }^{6,35}$ Muitos autores apontam também, como possível solução, a implementação de protocolos de atuação específicos para este tipo de abuso. ${ }^{6,10,13,18,27}$

Para além de melhorar a formação dos profissionais que contactam com a população geriátrica, no intuito de prevenir futuras situações abusivas, é também necessário promover a consciencialização da sociedade. ${ }^{1,10-11,22,24,28,34,36}$ É necessário alertar o público em geral para os vários tipos de abuso, os seus sinais e sintomas, o processo de denúncia e quais as instituições disponíveis para ajudar as vítimas, ${ }^{1,10-11}$ evidenciando também as suas consequências e a importância da deteção precoce. ${ }^{28}$ Devem ainda aprimorar-se as políticas e práticas das instituições de cuidados para idosos, melhorando o seu ambiente físico e social, ${ }^{1,11}$ e equacionar a implementação de programas de apoio ao cuidador ${ }^{1,11}$ que permitam o seu descanso e reduzam a probabilidade de este se tornar abusivo para com o idoso.

Para terminar, é de extrema importância referir que, apesar do crescente interesse sobre esta temática, a maioria dos países não dispõe de legislação específica que abranja o abuso de idosos. ${ }^{1}$ De acordo com o ReLA-
TÓRIO MUNDIAL SOBRE A PREVENÇÃO DA VIOLÊNCIA 2014, apesar de 75 a $80 \%$ dos países afirmarem que dispõem de leis para prevenir a violência, somente 30 a $70 \%$ dispõem de leis que impedem a prática de atos abusivos contra as pessoas idosas. ${ }^{11}$ É também realçado o facto de que, entre todos os serviços disponíveis para ajudar as vítimas de todo o tipo de violência, os serviços de proteção aos idosos são os menos referidos, com somente um terço dos países a relatar possuir serviços para investigar os possíveis casos de abuso de idosos e fornecer apoio a idosos vulneráveis. ${ }^{11}$ É ainda crucial destacar que a implementação de medidas para prevenir o abuso de idosos tem sido limitada, com apenas $26 \%$ dos países a relatar a implantação em larga escala de atividades para aperfeiçoar o conhecimento dos profissionais de saúde sobre o tema em questão e $23 \%$ a relatar ter implantado campanhas de consciencialização ao público. ${ }^{11}$ Em África, na América e no Sudeste Asiático, a maior parte dos países admitiu ter realizado campanhas de consciencialização apenas esporadicamente. ${ }^{11}$

\section{Breve noção da realidade portuguesa}

Segundo as estatísticas disponibilizadas pela DGS e pela APAV, em Portugal as pessoas idosas vítimas de abuso são frequentemente mulheres, entre 60 e 69 anos, casadas, reformadas, com baixo grau de escolaridade e que pertencem a uma família de tipo nuclear com filhos. ${ }^{21,39}$

Comparativamente a outros países da Europa, Portugal detém a prevalência mais alta de abuso psicológico, físico, financeiro e sexual, ${ }^{3}$ sendo os abusos considerados mais frequentes na população idosa portuguesa o financeiro e o psicológico. ${ }^{10,38}$ Relativamente ao abuso sexual, este pode ser ocultado pelo facto de o sexo na população idosa ainda ser visto como um tabu na nossa sociedade. ${ }^{9}$

Apesar de muitas vezes os comportamentos abusivos serem algo que se repete ao longo do tempo, é chocante que a maioria das vítimas não o denuncie. ${ }^{9}$ No estudo de Gil e colaboradores apenas um terço das vítimas procurou ajuda. ${ }^{38}$ Mesmo quando o abuso é exposto, $13,5 \%$ das vítimas recusou identificar o abusador; ${ }^{10,38}$ contudo, no caso do abuso financeiro, este número aumentou para $22,3 \%$, o que pode fazer suspeitar de uma possível subestimação deste problema. ${ }^{38}$ 
Apesar de existirem vários obstáculos à denúncia dos casos de abuso de idosos pelos profissionais de saúde, como referido anteriormente, os profissionais inquiridos tendem a relevar, considerando como patognomónico de abuso a presença de lesões em diferentes estádios de evolução e sinais de constrição física. ${ }^{6}$

No que diz respeito à perspetiva dos profissionais de saúde sobre a obrigatoriedade de denunciar um caso suspeito de abuso de idosos, o mesmo estudo afirma que $63 \%$ da amostra considerou que é obrigatório denunciar às autoridades qualquer suspeita de comportamentos abusivos contra pessoas idosas; no entanto, $28,4 \%$ não sabia se era obrigatório ou não denunciar, sendo que $26,8 \%$ ainda hesitaria mesmo depois do idoso expor que é vítima de abuso. ${ }^{6}$ Para realizar a queixa, a maioria dos profissionais considera apenas os Serviços Sociais e o Ministério Público. ${ }^{6}$ De notar que a queixa pode ser apresentada pela vítima ou a denúncia por outrem aos órgãos de Polícia Criminal (Guarda Nacional Republicana, Polícia de Segurança Pública ou Polícia Judiciária), às Delegações ou Gabinetes Médico-Legais e Forenses do Instituto Nacional de Medicina Legal e Ciências Forenses, no portal Queixas Eletrónicas do Ministério da Administração Interna ou, em alguns casos, ao Serviço de Estrangeiros e Fronteiras. ${ }^{21}$ É possível denunciar estes casos mesmo que não se saiba a identidade do autor, pois a identificação é uma função que compete às autoridades na sua investigação subsequente. ${ }^{21}$

No que concerne ao receio dos clínicos sobre a quebra do Código Deontológico por violação do segredo médico, deve realçar-se que o respetivo artigo $27 .^{\circ}$ na redação atual prescreve que os médicos, no intuito de protegerem os idosos, devem tomar providências adequadas e alertar autoridades competentes sem temerem eventuais consequências disciplinares. ${ }^{40}$ Já o Código Deontológico dos Enfermeiros, no artigo 102. ${ }^{\circ}$, reforça a ideia de que o enfermeiro deve salvaguardar os direitos da pessoa idosa; sendo que, pelo artigo 106. nas situações previstas na lei, o enfermeiro assume o dever de divulgar informação confidencial. ${ }^{41}$

Relativamente ao abusador e às punições previstas no Código Penal, o artigo 152..$^{-A}$ prevê que quem infligir maus-tratos a pessoa idosa é punido com pena de prisão de um a cinco anos..$^{42}$ É ainda de referir que também pode ser aplicado o artigo 152. ${ }^{\circ}$, que antevê que quem infligir maus-tratos a cônjuge/parceiro (atual ou ex) ou a pessoa idosa com quem coabite é punido com pena de prisão de um a cinco anos. ${ }^{42}$ Além do referido nos artigos $152 .^{\circ} \mathrm{e} 152 .^{\circ}$-A, existem outros tipos de atos abusivos que são abrangidos por artigos diferentes do Código Penal. Pode referir-se, por exemplo, o artigo $143 .^{\circ}$, sobre integridade física simples; o artigo $203 .^{\circ}$, sobre furto; e $\mathrm{o}$ artigo $210 .^{\circ}$, referente ao roubo. ${ }^{42}$

No que diz respeito às estratégias para a prevenção de abuso na população geriátrica portuguesa, o ReLATÓRIO MUNDIAL SOBRE A PREVENÇÃO DA VIOLÊNCIA 2014 apurou que foram implantadas em larga escala campanhas de consciencialização de profissionais de saúde e programas de apoio ao cuidador; todavia, apenas foram realizadas campanhas de consciencialização dirigidas ao público em geral ocasionalmente. ${ }^{11}$

Em face do exposto poder-se-á afirmar que, embora reconhecendo os múltiplos passos já concretizados no sentido de melhorar o panorama nacional, se considera ser indiscutível que existe ainda um longo caminho a percorrer, nomeadamente visando melhorar a consciencialização pública sobre o abuso de idosos $\mathrm{e}$ a prevenção deste tipo de situações.

\section{CONCLUSÕES}

O abuso de idosos, apesar de claramente referenciado como um problema social de caráter global (afetando todas as classes socioeconómicas) desde pelo menos a década de 70 do século passado, somente num passado recente se transformou num tema de maior interesse social, político e mediático, circunstância em provável relação com o aumento exponencial da população mais idosa.

A exposição dos idosos a fenómenos abusivos acarreta impactos relevantes para a sua saúde físico-psíquica, podendo conduzir a situações mais graves e até potencialmente letais. É, deste modo, relevante a tónica colocada na deteção precoce e subsequente orientação adequada destes casos e o contributo indispensável dos profissionais de saúde para a concretização deste desiderato, assumindo particular destaque os profissionais de cuidados de saúde primários face à sua estreita interligação com a população geriátrica.

Diversos fatores podem estar a influenciar a capacidade destes profissionais em reconhecerem e orientarem situações abusivas perpetradas contra pessoas idosas, destacando-se, entre os diversos aspetos aponta- 
dos na literatura, as lacunas na formação. Importa, pois, melhorar a formação curricular básica, mas também a obtida no decurso da vida profissional, de forma a alcançar níveis superiores de sensibilização e de competência na identificação e gestão destes casos. Entende-se, contudo, que deverão ser reconhecidos fatores perturbadores, exógenos ao profissional de saúde, que deverão ser devidamente equacionados aquando da implementação de estratégias que visem a melhoria da intervenção daqueles profissionais.

Apesar do justificado enfoque dado à relevância dos profissionais de saúde no âmbito desta temática, crê-se ser de realçar que a prevenção da violência em geral e, de forma mais particular, aquela que é perpetrada contra pessoas potencialmente mais vulneráveis, deverá resultar de um esforço de consciencialização coletiva para a necessidade de controlar a agressividade interrelacional, sendo que também cabe a todos e a cada um de nós, como cidadãos, participar nos esforços desenvolvidos para a deteção e intervenção precoce em situações problemáticas.

\section{REFERÊNCIAS BIBLIOGRÁFICAS}

1. Krug EG, Dahlberg LL, Mercy JA, Zwi AB, Lozano R. Relatório mundial sobre violência e saúde [Internet]. Genebra: Organização Mundial da Saúde; 2002. Available from: https://www.opas.org.br/wpcontent/uploads/2015/09/relatorio-mundial-violencia-saude.pdf

2. Fisher JM, Rudd MP, Walker RW, Stewart J. Training tomorrow's doctors to safeguard the patients of today: using medical student simulation training to explore barriers to recognition of elder abuse. J Am Geriatr Soc. 2016;64(1):168-73.

3. Eslami B, Viitasara E, Macassa G, Melchiorre MG, Lindert J, Stankunas $M$, et al. The prevalence of lifetime abuse among older adults in seven European countries. Int J Public Health. 2016;61(8):891-901.

4. Loh DA, Choo WY, Hairi NN, Othman S, Hairi FM, Mydin FH, et al. A cluster randomized trial on improving nurses' detection and management of elder abuse and neglect (I-NEED): study protocol. J Adv Nurs. 2015;71(11):2661-72.

5. Gil AP, Santos AJ, Kislaya I, Santos C, Mascoli L, Ferreira Al, et al. Estudo sobre pessoas idosas vítimas de violência em Portugal : sociografia da ocorrência [A sociography of elderly victims of family violence in Portugal]. Cad Saúde Pública. 2015;31(6):1234-46. Portuguese

6. Ferreira $M$, Santos CL, Vieira DN. Detection and intervention strategies by primary health care professionals in suspected elder abuse. Acta Med Port [Internet]. 2015;28(6):687-94.

7. Vetere PM. Elder abuse: what are we missing? Can Fam Physician. 2011;57(7):783-5.

8. Martins R, Neto MJ, Andrade A, Albuquerque C. Abuse and maltreatment in the elderly. Aten Primaria. 2014;46(Suppl 5):206-9.

9. Frazão SL, Silva MS, Norton P, Magalhães T. Domestic violence against elderly with disability. J Forensic Leg Med. 2014;28:19-24.

10. Gil AP, Santos AJ, Kislaya I, Nicolau R. Envelhecimento e violência [Internet]. Lisboa: Instituto Nacional de Saúde Dr. Ricardo Jorge; 2014. Available from: http://repositorio.insa.pt/handle/10400.18/1955

11. Organização Mundial da Saúde. Relatório mundial sobre a prevenção da violência 2014 [Internet]. São Paulo: Núcleo de Estudos da Violência da Universidade de São Paulo; 2015. Available from: http://nevusp.org/wp-content/uploads/2015/11/1579-VIP-Main-report-Pt-Br26-10-2015.pdf

12. Hoover RM, Polson M. Detecting elder abuse and neglect: assessment and intervention. Am Fam Physician. 2014;89(6):453-60.

13. Cairns J, Vreugdenhil A. Working at the frontline in cases of elder abuse: 'It keeps me awake at night'. Australas J Ageing. 2014;33(1):59-62.

14. Dow B, Hempton C, Cortes-Simonet EN, Ellis KA, Koch SH, Logiudice $D$, et al. Health professionals' and students' perceptions of elder abuse. Australas J Ageing. 2013;32(1):48-51.

15. Pelotti S, D'Antone E, Ventrucci C, Mazzotti MC, Salsi G, Dormi A, et al. Recognition of elder abuse by Italian nurses and nursing students: evaluation by the Caregiving Scenario Questionnaire. Aging Clin Exp Res. 2013;25(6):685-90.

16. Sandmoe A, Kirkevold M. Identifying and handling abused older clients in community care: the perspectives of nurse managers. Int J Older People Nurs. 2013;8(2):83-92.

17. Hempton C, Dow B, Cortes-Simonet EN, Ellis K, Koch S, LoGiudice D, et al. Contrasting perceptions of health professionals and older people in Australia: What constitutes elder abuse? Int J Geriatr Psychiatry. 2011;26(5):466-72.

18. Daly J, Coffey A. Staff perceptions of elder abuse. Nurs Older People. 2010;22(4):33-7.

19. Burston GR. Granny-battering [letter]. Br Med J. 1975;3(5983):592.

20. Baker AA. Granny battering. Mod Geriatr. 1975;8(5):20-4.

21. Direção-Geral da Saúde. Violência interpessoal: abordagem, diagnóstico e intervenção nos serviços de saúde [homepage]. Lisboa: DGS; 2016. Available from: https://www.dgs.pt/?cr=34067

22. Fraga S, Lindert J, Barros H, Torres-González F, loannidi-Kapolou E, Melchiorre MG, et al. Elder abuse and socioeconomic inequalities: a multilevel study in 7 European countries. Prev Med. 2014;61:42-7.

23. Lindert J, De Luna J, Torres-Gonzales F, Barros H, loannidi-Kopolou E, Melchiorre MG, et al. Abuse and neglect of older persons in seven cities in seven countries in Europe: A cross-sectional community study. Int J Public Health. 2013;58(1):121-32.

24. Almogue A, Weiss A, Marcus EL, Beloosesky Y. Attitudes and knowledge of medical and nursing staff toward elder abuse. Arch Gerontol Geriatr. 2010;51(1):86-91.

25. Dong XQ. Screening for elder abuse in healthcare settings: why should we care, and is it a missed quality indicator? J Am Geriatr Soc. 2015;63(8):1686-8.

26. Rosen T, Lien C, Stern ME, Bloemen EM, Mysliwiec R, McCarthy TJ, et al. Emergency medical services perspectives on identifying and reporting victims of elder abuse, neglect, and self-neglect. J Emerg Med. 2017;53(4):573-82.

27. Leddy MA, Farrow VA, Schulkin J. Obstetrician-gynecologists' knowledge, attitudes, and practice regarding elder abuse screening. Womens Health Issues. 2014;24(4):e455-64. 
28. Wagenaar DB, Rosenbaum R, Page C, Herman S. Primary care physicians and elder abuse: current attitudes and practices. J Am Osteopath Assoc. 2010;110(12):703-11.

29. Schmeidel AN, Daly JM, Rosenbaum ME, Schmuch GA, Jogerst GJ Healthcare professionals' perspectives on barriers to elder abuse detection and reporting in primary care settings. J Elder Abuse Negl. 2012;24(1):17-36.

30. Hullick C, Carpenter CR, Critchlow R, Burkett E, Arendts G, Nagaraj G, et al. Abuse of the older person: is this the case you missed last shift? Emerg Med Australas. 2017;29(2):223-8.

31. Dong XQ. Elder abuse: systematic review and implications for practice. J Am Geriatr Soc. 2015;63(6):1214-38.

32. Du Mont J, Kosa D, Macdonald S, Elliot S, Yaffe M. Determining possible professionals and respective roles and responsibilities for a model comprehensive elder abuse intervention: a Delphi consensus survey. PLoS One. 2015;10(12):e0140760.

33. Vognar L, Gibbs LM. Care of the victim. Clin Geriatr Med. 2014;30(4):869-80.

34. O'Brien JG, Riain AN, Collins C, Long V, O'Neill D. Elder abuse and neglect: a survey of Irish general practitioners. 2014;26(3):291-9.

35. Reingle-Gonzalez JM, Cannell MB, Jetelina KK, Radpour S. Barriers in detecting elder abuse among emergency medical technicians. BMC Emerg Med. 2016;16(1):36.

36. O'Brien JG. Screening for elder abuse and neglect. J Am Geriatr Soc. 2015;63(8):1689-91.

37. Daly JM, Klein AN, Jogerst GJ. Critical care nurses' perspectives on elder abuse. Nurs Crit Care. 2012;17(4):172-9.
38. Gil AP, Kislaya I, Santos AJ, Nunes B, Nicolau R, Fernandes AA. Elder abuse in Portugal: findings from the First National Prevalence Study. J Elder Abuse Negl. 2015;27(3):174-95.

39. Associação Portuguesa de Apoio à Vítima. Pessoas idosas vítimas de crime e de violência 2013-2016 [Internet]. Lisboa:APAV; 2017. Available from: https://apav.pt/intranet16/images/formacao/PDF/Estatisticas_APAV_Pessoas_Idosas_2013_2016.PDF

40. Regulamento n. ${ }^{\circ} 707 / 2016$, de 21 de julho. Diário da República. $2^{\text {a }}$ Série(139):22575-88.

41. Decreto-Lei n. ${ }^{\circ}$ 104/98, de 21 de abril. Diário da República. $1^{\text {a Série- }}$ A(93):1739-57.

42. Decreto-Lei n. ${ }^{\circ}$ 48/95, de 15 de março. Diário da República. $1^{\text {a }}$ SérieA(63):1350-416

\section{CONFLITO DE INTERESSES}

Os autores declaram não ter quaisquer conflitos de interesse.

\section{FONTES DE FINANCIAMENTO}

Os autores declaram que nenhum subsídio contribuiu para este trabalho.

\section{ENDEREÇO PARA CORRESPONDÊNCIA}

Inês Filipa Santos Almeida

E-mail: inesfsalmeida@hotmail.com

https://orcid.org/0000-0003-0948-8754

Recebido em 13-09-2018

Aceite para publicação em 11-05-2019

\section{ABSTRACT}

\section{ELDER ABUSE AND THE ROLE OF HEALTH PROFESSIONALS}

Objectives: Analyze the professionals' perspective on elder abuse and to explore the difficulties they experience in addressing this type of situation. Furthermore, a review was made on some fundamental concepts related to this subject.

Data sources: Research in the following databases PubMed, MEDLINE, Embase, Scientific Repositories of Open Access of Portugal and OpenAIRE. It was also consulted Code of Conduct of the Portuguese Medical Association, Code of Conduct of Nurses, Portuguese Penal Code and the information provided in the websites of the World Health Organization, General-Directorate of Health and the Portuguese Association for Victim Support.

Review methods: Database research by combining the following terms: elder abuse; mistreatment; elderly; health professionals; health personnel; health care personnel; Portugal.

Results: Thirty-two original scientific articles, published between 2010 and 2018, all of which were available in Portuguese and/or English, with content directed to the proposed objectives.

Conclusions: Lacks in detection and management by health professionals of abusive situations against the elderly may be associated with deficits in education on this topic, thus it is crucial to improve curricular content. Training should focus on situations that may be considered abusive, associated signs and symptoms, the context in which abuse may occur, the existing legislation and entities that may provide assistance. In addition, public awareness should be promoted, emphasizing the importance of early detection and identifying institutions that provide support to the vulnerable elderly.

Keywords: Elder abuse; Aged; Health personnel; Portugal. 